\title{
UMA PROPOSTA DE EDUCAÇÃO EMPREENDEDORA PARA PESSOAS MADURAS
}

Marcos Primo ${ }^{1}$

${ }^{1}$ Universidade Federal de Pernambuco - UFPE 


\section{UMA PROPOSTA DE EDUCAÇÃO EMPREENDEDORA PARA PESSOAS MADURAS}

Resumo: Pessoas maduras (acima de 50 anos) sentem-se limitadas para desenvolverem suas carreiras profissionais no Brasil. Muitos se aposentam antes de serem oficialmente considerados idosos. Por outro lado, boa parte delas está em plenas condições produtivas, muito embora o mercado de trabalho se feche para eles. Esse artigo busca analisar as condições para que pessoas maduras utilizem o empreendedorismo como opção de uma nova carreira profissional. Utilizando-se de pesquisa bibliográfica e relatórios, serão discutidos os números do empreendedorismo maduro, assim como as vantagens e desvantagens dessas pessoas como potenciais empreendedores. Verifica-se que as atuais ações de estímulo ao empreendedorismo são predominantemente destinadas ao público jovem e a maior dificuldade para os potenciais empreendedores maduros trata-se da falta de uma educação empreendedora adequada. Discutimos a metodologia Effectuation como importante para essa preparação, assim como o uso de ferramentas tais como a Mentoria, o Design Thinking, para adequar programas de educação empreendedora para esse tipo de público.

Palavras-chave:Empreendedorismo

Maduro.

Effectuation.

Educação Empreendedora.Mentoria. 


\section{Introdução}

$\mathrm{Na}$ década de 60 a expectativa média de vida no Brasil era de 50 anos. Atualmente, saltou para 75,8 anos. Somos 208 milhões e $21,6 \%$ da população brasileira (44 milhões) têm mais que 50 anos (IBGE 2017). Considerando-se que até 2030 teremos mais pessoas acima de 50 anos do que abaixo de 15 anos (IBGE 2013), um quantitativo cada vez maior de pessoas maduras estará buscando oportunidades na vida profissional, seja pela limitação e falta de autonomia do emprego atual, seja pelo desejo de equilibrar a vida pessoal com a vida familiar e poder controlar a própria agenda (Harms et al. 2014). Com a aproximação ou efetivação da aposentadoria, muitas dessas pessoas se colocam em um dilema: continuar trabalhando ou encerrar essas atividades para "aproveitar mais a vida".

Aqueles que optarem por continuar trabalhando terão limitadas condições no mercado de trabalho atual, ou mesmo buscarão uma condição de trabalho mais equilibrada com as suas condições de entusiasmo e saúde. Considerando-se que a maior experiência das pessoas maduras estaria associada a maiores salários e organizações preferem moldar seus recursos humanos a partir de idades mais baixas, a empregabilidade dos novos aposentados no mercado de trabalho diminui sensivelmente. Assim, trabalhar por conta própria ou empreender torna-se uma opção para o desenvolvimento profissional dessas pessoas (Singh \&DeNoble 2005).

O empreendedorismo comandado por pessoas maduras tem crescido no Brasil e no mundo. Nos Estados Unidos, 23,4\% das novas empresas foram abertas por pessoas com idades entre 55 e 64 anos e esse percentual de empreendedores tem crescido ao longo dos últimos anos (Kaufmann Foundation, 2014). Já no Brasil, segundo o Global EntrepreneurshipMonitor-GEM, 12,1\% dos novos empreendedores têm entre 45 e 54 anos e $8,3 \%$ deles (grupo de maior crescimento) têm mais de 55 anos (GEM, 2015).

Uma preocupação do empreendedorismo de pessoas maduras seria a sustentabilidade dos negócios abertos por esse grupo. Entretanto, estudos apontam que a probabilidade de uma empresa aberta por um empreendedor maduro é significativamente maior que aquelas abertas por empreendedores jovens. CressyandStorey (1995), levantaram que na Inglaterra apenas $19 \%$ dasnovas empresas criadas por jovens sobreviviam os seis primeiros anos, enquanto esse número subia para $70 \%$ quando criadas por pessoas acima de 55 anos. Mais recentemente verificou-se que no Reino Unido, $70 \%$ dos empreendimentos criados por pessoas acima de 50 anos duravam pelo menos 5 anos, comparados a 28\% de dos empreendimentos bemsucedidos criados por jovens empreendedores (CMI 2014).

Apesar da crescente importância dos empreendedores maduros, a estrutura de divulgação e aprendizado do empreendedorismo tem sido voltada para pessoas mais jovens. Quando se analisa as atividades e o material de apoio das principais organizações que difundem o empreendedorismo no Brasil, verifica-se que o foco dessa formação é voltado para jovens (especialmente estudantes). Eventos tradicionais de empreendedorismo como a Campus Party e os diversos Startup Weekends que são realizados regularmente nas principais

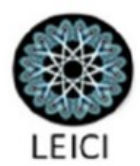


cidades brasileiras, têm público composto na vasta maioria por jovens e adolescentes.Hoje, asuniversidades brasileiras têm centros de empreendedorismos ou incubadoras, ou mesmo empresas júniores que proporcionam aos alunos (geralmente jovens) uma formação empreendedora.

Infelizmente, a percepção do empreendedorismo como atividade voltada para jovens é presente até mesmo entre os atuais empregados de meia-idade brasileiros. Eles tiveram na sua juventude uma formação voltada para conseguir emprego em uma grande empresa ou, principalmente uma posição no setor público brasileiro, que em várias regiões do país era o grande gerador de empregos. Muitas das atuais pessoas maduras nem sequer consideraram no passado o empreendedorismo como uma opção para as suas carreiras.O enfoque na criação de novas empresas de tecnologia (startups) e a valorização de projetos empreendedores de alto impacto com altos retornos, mas também altos riscos, de certa forma intimida a criação de novos empreendedores maduros.

A discussão supracitada mostra a crescente importância do empreendedorismo de pessoas maduras. Entretanto, esse movimento não tem sido incentivado pela estrutura de empreendedorismo no país. Entendemos que parte dessas dificuldades vem da falta de uma educação empreendedora mais alinhada com o público maduro. Seria interessante então, entender os fatores que influenciam o empreendedorismo maduro, assim como as características desse público empreendedor. Dessa forma, poderíamos entender as limitações da educação empreendedora disponível para atender os empreendedores maduros, e propor uma educação empreendedora mais alinhada com os perfis dessas pessoas.A justificativa desse trabalho apoia-se no rápido envelhecimento da população brasileira, e na possibilidade de continuidade da participação dessas pessoas no desenvolvimento socioeconômico do país através do empreendedorismo.

\section{Fatores e Características do Empreendedor Maduro}

Estudos de Economia do Trabalho tentam analisar fatores afetando o empreendedorismo maduro. Singh \&DeNoble (2003) apontam quatro fatores afetando a decisão de um novo aposentado, continuar ou retornar ao trabalho: a condição financeira; a saúde; o apego ao trabalho; e as condições de empregabilidade na sua região ou país. Assim, a falta de uma boa reserva financeira, boas condições de saúde, apego ao trabalho, e razoáveis condições de empregabilidade levariam o aposentado a continuar suas atividades laborais. Já Lévesque\&Minniti (2006) apresentaram um modelo em que indivíduos definem uma trajetória de carreira de acordo com considerações sobre, idade, riqueza, e aversão ao risco. Eles encontraram que a demora para os retornos financeiros de um novo negócio, dificultariam o empreendedorismo maduro, tendo em vista que atividades que tenham retorno imediato atrairiam mais as pessoas mais velhas do que empreendimentos que demorariam a trazer retornos.

Mais recentemente, Harms et al. (2014) procuraram ampliar o fenômeno do empreendedorismo maduro para pessoas entre 50 e 65 anos de idades. Eles apontam três tipos

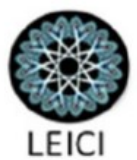


de fatores afetando a decisão de empreender de uma pessoa madura: fatores de push (negativos) e pull (positivos); normas sociais; e a habilidade do potencial empreendedor desempenha comportamentos específicos. Esses autores encontraram que o desalinhamento entre objetivos pessoais e condições de trabalhos é fator crítico do empreendedorismo de pessoas maduras e que a percepção de redes pessoais e da família também influenciavam a decisão de empreender dessas pessoas.

Um ponto que permeia vários trabalhos sobre empreendedores maduros é a capacidade de resgatarem sonhos antigos após terem resolvido pendências familiares e financeiras (Singh \&DeNoble 2003, Harms et al. 20014).Nesse sentido, Logan (2014) verificou que o gatilho para mulheres maduras empreenderem seria a necessidade de darem vazão a auto-realização e criatividade. Mais da metade das mulheres analisadas no estudo, afirmaram que a redução significativa das responsabilidades familiares era a ocasião para buscarem a realização de seus sonhos. A maioria delas empreendeu em áreas não relacionadas à experiência prévia de trabalho.

Além dos fatores afetando a decisão de empreender, é interessante discutir os tipos de empreendedores maduros. Nesse sentido, a tipologia de empreendimento maduro mais difundida tem sido a apresentada por Singh \&DeNoble (2003). Aqueles autores identificam três tipos de empreendedores: constrangidos, racionais e relutantes. Os constrangidos são aqueles que sempre quiseram empreender, mas que, por razão profissionais e/ou pessoais foram adiando esse projeto e, com a idade madura, acham que é o momento. Os Racionais são pessoas maduras que consideram o empreendedorismo como uma escolha racional para continuarem suas realizações profissionais. Por fim, os relutantes são pessoas maduras que só consideram o empreendedorismo por falta de opções profissionais ou como uma necessidade de complementação de renda. Ahmad et al. (2013) encontraram que tipos de empreendedores estariam associados a diferentes propósitos. Eles encontraram que os direcionadores para os empreendedores racionais na Malásia seriam a progressão de carreira, aumentos dos ganhos financeiros, proporcionar maior segurança familiar,ter uma vida mais balanceada,

Os trabalhos anteriormente descritos falam de recursos da pessoa madura para empreender comparados ao de uma pessoa mais jovem. Harms et al. (2013) encontraram que o fator experiência profissional aumentava significativamente a confiança das pessoas maduras para empreenderem. Maior tempo disponível seria um recurso importante para uma pessoa madura utilizar em um projeto empreendedor, especialmente após a aposentadoria. Entretanto, outros tipos de recurso seriam cruciais para o desenvolvimento desse projeto (Primo 2017). Uma maior capacidade de se autofinanciar geralmente acompanha as pessoas maduras. Os profissionais maduros teriam várias vantagens ligadas ao capital que têm acumulado ao longo da sua vida. Geralmente alguma reserva financeira está disponível no momento da aposentadoria. Além disso, o aprendizado muitas vezes ligados a atividades de negócios e uma rede de contatos associada seriam vantagens de um novo aposentado comparado a uma pessoa mais jovem. Finalmente, não pode ser desprezada a experiência de vida e o histórico associado de sucessos e falhas de uma pessoa madura. Podemos resumir esses pontos no quadro a seguir:

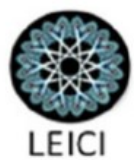




\begin{tabular}{|l|l|}
\hline Tipo de Capital & \multicolumn{1}{|c|}{ Descrição } \\
\hline Capital Financeiro & $\begin{array}{l}\text { Posição financeira geralmente mais favorável devido ao que } \\
\text { conseguiram construir e/ou poupar por longos anos de trabalho }\end{array}$ \\
\hline Capital Intelectual & $\begin{array}{l}\text { Anos de experiência profissional fazem com que essas pessoas tenham } \\
\text { um acúmulo de conhecimento }\end{array}$ \\
\hline Capital Social & Maior rede de contatos construída ao longo dos anos \\
\hline Capital Emocional & Desenvolvimento de resiliência devido à dificuldades enfrentadas \\
\hline
\end{tabular}

Quadro I - Tipos de capital associados a pessoas maduras (desenvolvido pelo autor)

Apesar dessas vantagens, empreendedores maduros também possuem desvantagens. Uma delas é a desconfiança das pessoas mais novas em relação à capacidade empreendedora das pessoas maduras, especialmente em setores como o de tecnologia da informação e de novas tecnologias que requerem constantes atualizações e qualificações. Essa desconfiança aparentemente seria menor em sociedades consideradas mais maduras. De fato, a literatura aponta que normas sociais podem ser um grande obstáculo na intenção de empreender para esse público (Kautone et al. 2011). Esses autores encontraram que a percepção positiva da população finlandesa quanto ao empreendedorismo sênior estimula projetos empreendedores desse público. Entretanto, acreditamos que essas atitudes não necessariamente seriam a mesma em países emergentes como o Brasil, onde a população ainda é majoritariamente jovem e há uma percepção negativa da contribuição de pessoas maduras para o empreendedorismo.

Uma questão que se coloca é que pessoas maduras necessitam desenvolver a capacidade de empreender, especialmente aqueles que nunca tiveram uma experiência empreendedora antes, ou mesmo contato direto com o empreendedorismo. De fato, Curran\& Blackburn (2002), analisando empregados próximos da aposentadoria simpáticos à ideia de empreender no Reino Unido, mostraram que boa parte deles (39\%) se achavam com pouco conhecimento para comandar uma empresa (mesmo que pequena) e $30 \%$ deles não tinham uma ideia de negócio. Indivíduos de meia-idade têm mais intenção em empreender quanto mais eles percebem sua capacidade em gerir um negócio (Kautonen et al. 2011)

Apesar do considerável capital das pessoas maduras (vide Quadro I), muitos dos seus recursos podem não se converter em capacidade empreendedora. Além disso, essas pessoas têm dificuldades específicas da sua faixa etária como discutido anteriormente. É muito importante que haja investimentos em qualificação para o desenvolvimento da capacidade empreendedora desse público. Um pressuposto deste trabalho é que ações de educação empreendedora são voltadas para os mais jovens e não endereçam questões típicas de empreendedores maduros, como as anteriormente descritas. Entendemos que seria interessante abordagens de metodologias empreendedoras que reforcem o capital das pessoas

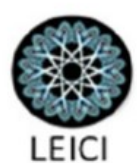


maduras, assim como leve em conta as suas limitações. Com esse pensamento, discutiremos na próxima seção uma proposta de educação empreendedora voltada para esse público.

\section{Uma Proposta de Educação Empreendedora}

Metodologias de educação empreendedora têm sido utilizadas para ajudar novos empreendedores em seus projetos. Pessoas maduras ao buscarem uma formação empreendedora têm dificuldade com a qualificação dirigida para startups e público jovem disponibilizada em universidades, escolas e organizações de apoio ao empreendedorismo.Por exemplo, a educação empreendedora tradicional focaliza a busca de oportunidades de mercado e a arregimentação de meios e recursos para realiza-las. Trata-se da lógica causal, onde os objetivos empreendedores são fixados e buscam-se arranjar os meios para obtenção dessas metas pré-determinadas. Projetos empreendedores competem ferozmente pela atração de investidores para decolarem ou escalarem seus negócios. Nesse ambiente, pessoas de meiaidade sentem-se desencorajadas a competir por investimentos com os jovens empreendedores.

O empreendedorismo tem sido estudado (1) como um conjunto de traços de personalidade do empreendedor que explicam o sucesso ou o insucesso das firmas que criam, ou (2) como um conjunto de circunstâncias ou atributos da oportunidade e da sua envolvente que contém as sementes do seu sucesso ou insucesso (Saravasthny 2001) Segundo a autora, a educação empreendedora procura desenvolver alguns traços empreendedores ou treinar potenciais empreendedores a desenvolver estratégias e habilidades para reconhecer, identificar e explorar oportunidades de elevado potencial. Ela propôs uma metodologia alternativa (effectuation) para explicar o sucesso de empreendedores baseada em seus pontos comuns em vez de e empreendedores de traços ou habilidades específicas. Essa metodologia adota uma lógica inversa para o caminho empreendedor, onde os objetivos não são fixos e amarrados a uma oportunidade de negócio prevista, e sim alinhados com os meios e recursos do empreendedor. Como os empreendedores maduros tendem a acumular significativos recursos (vide Quadro I) ao longo de suas carreiras profissionais, é natural que eles utilizem essa vantagem para empreender.

Vários resultados na literatura apontam que a metodologia Effectuation aplicada a projetos empreendedores, embora não reduza a probabilidade de fracasso, diminui seu custo, pois permite ao empreendedor falhar mais rapidamente (Sarasvathy, 2001). Essa metodologia também tem sido aplicada no ensino do empreendedorismo (Salusse\&Andreassi 2016). De acordo com aqueles autores que analisaram estudos de caso múltiplos de ensino do empreendedorismo no mundo, para o caso das pessoas que pretendem empreender, independentemente da motivação ou situação, há evidências no sentido de que a teoria influencia positivamente a intenção das mesmas.

$\mathrm{Na}$ metodologia Effectuationos meios são considerados como os recursos do empreendedor que procura diversos objetivos atingíveis através desses meios (Vide Figura 1).

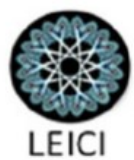




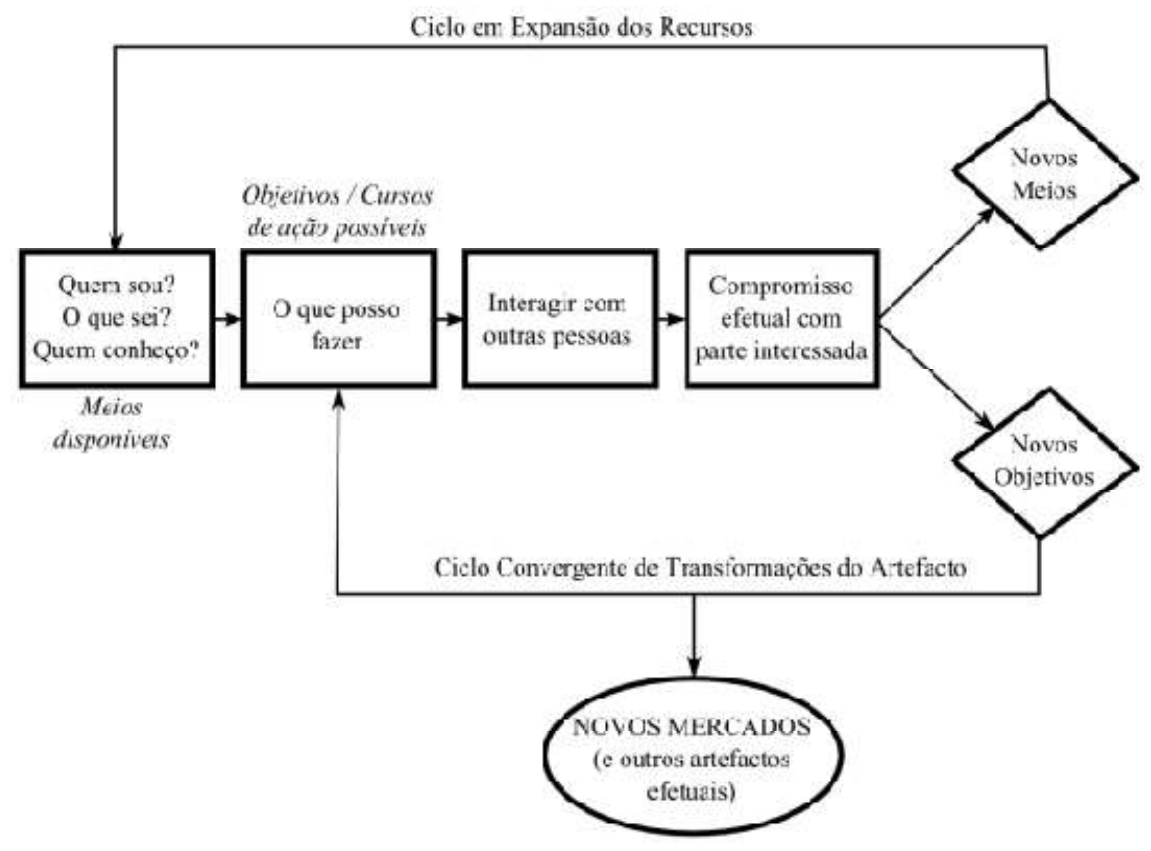

\section{Figura 1 - Ciclo da Metodologia Effectuation (fonte Sarasvathy 2001)}

A metodologia effectuation assume que o futuro não pode ser previsto, contrariamente ao empreendedorismo tradicional onde os planos de negócio detalhadamente fazem estimativas de vendas e de custos, que são constantemente revisadas e, muitas vezes abandonadas no confronto com os resultados reais do empreendimento. Essa metodologia se concentra em ações do empreendedor para alcançar várias opções de resultados futuros a partir dos meios atuais do empreendedor. O resultado dessas ações pode levar a redefinição de objetivos, assim como a atração de pessoas da rede do empreendedor pode levar a incorporação de novos recursos para o empreendimento.

Um ponto central desse trabalho seria a discussão das vantagens da aplicação da metodologia effectuation para a educação dos empreendedores maduros. O primeiro princípio da metodologia sugere que o empreendedor comece com os seus meios. Geralmente, jovens empreendedores são impulsionados a definirem um objetivo estratégico (efeito a ser alcançado) para seus empreendimentos e buscarem meios para poderem realiza-los. Por outro lado, a pessoa madura tem uma história de vida que lhe ajuda a conhecer suas forças e limitações (seus meios) e vai procurar objetivos que se alinhem a eles (lógica efetual). Esse princípio está alinhado com o papel da experiência na literatura de empreendedorismo maduro. Experiência é considerada um fator importante para a decisão de uma pessoa madura tornar-se um empreendedor (Harms et al. 2014). Entretanto, aqueles autores argumentam que a experiência do empreendedor apenas não garante longevidade de um negócio. De fato, a metodologia effectuation é colocada como mais adequada às fases iniciais de um negócio (Reed \&Sarasvathy 2005). 
Um aspecto crítico da metodologia effectuation trata-se do princípio das perdas aceitáveis (AcceptableLosses). Jovens empreendedores lançam-se em uma frenética busca para financiamento de seus projetos. Dependendo do investimento requisitado e do risco associado, muitos desses negócios não decolam. Por outro lado, a pessoa madura geralmente tem recursos (financeiros, tempo, etc.) que, se forem consumidos em um negócio, não a colocaria em uma situação de ter que recomeçar do ponto zero.

O conceito de perdas aceitáveis se adequa a resultados da literatura. Zissimopoulos\&Karoly (2007) afirmam que, devido à necessidade de investimentos, pessoas de meia-idade refletiriam que investimento em um novo empreendimento talvez corroam os proventos da aposentadoria, inibindo o empreendedorismo nesse grupo. Já Lévesque\&Minniti (2006) encontraram que pessoas mais velhas receariam empreender pois os retornos financeiros de um novo negócio geralmente demoram. Entendemos que ao investir em um negócio apenas aquilo que está disposta a perder ou que não corroesse os proventos de uma aposentadoria, uma pessoa madura não estaria buscando um rápido retorno daquele investimento, o que está de acordo com esse princípio.

Outro princípio da metodologia effectuation é o da "Manta de Retalhos Emergente" (Patchwork quilt). Nesse princípio, o empreendedor deve se conectar com quem importa para o seu projeto. A ideia seria formar parcerias com pessoas e organizações que estejam dispostas a se comprometer com o projeto empreendedor. Harms et al. (2014) encontrou que redes pessoais têm um papel importante no empreendedorismo de pessoas maduras. Eles encontraram que o apoio da família pode ser importante para o projeto empreendedor, enquanto a falta de apoio familiar não impediria o mesmo. De fato, a pessoa madura tem uma rede que é construída mais em relacionamentos face-a-face do que relacionamentos virtuais como os mais jovens, que impacta a confiança na criação de negócios. Contatos incluindo familiares, ex-colegas de profisssão, representantes de fornecedores, etc., são importantes fontes de troca de ideias. A vivência da pessoa madura favorece a conexão com que se importa com o sucesso do negócio favorecendo a colaboração externa.

Um outro princípio da metodologia effectuation é o princípio da limonada (lemonade). Assim, um empreendedor experiente deve focar em atividades que estão sob seu controle e estar preparado para mudanças. Em vez de tentar lutar contra mudanças no ambiente de negócios como geralmente é feito pelas pessoas mais jovens, esse empreendedor busca extrair o melhor possível da nova situação. Empreendedores bem-sucedidos concentram-se naquilo que conseguem fazer e fazem-no, sem se preocuparem com o que deviam fazer (Sarasvathy 2001). Essa capacidade de adaptação é peculiar de um empreendedor maduro como consequência de vários ajustes oriundos de sua experiência profissional. Dessa forma, o ajuste/mudança de objetivos conforme sugerido pela metodologia e presente no empreendedorismo maduro, seria bastante adequado às etapas iniciais de um novo negócio.

O princípio do piloto no avião (Pilotonthe plane) reforça a importância de considerar a agência humana como o principal impulsionador da oportunidade, por oposição a limitar os esforços empreendedores à exploração de fatores exógenos como trajetórias tecnológicas e

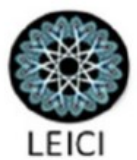


tendências socioeconómicas. Esse princípio está baseado no pressuposto da metodologia effectuationde que o futuro não pode ser encontrado nem previsto, mas pode ser criado. Esse princípio retrata bem o desejo de empreendedores maduros de controlar suas agendas em vez de tê-las determinadas por empregadores como ocorreu nas suas carreiras profissionais.

Obviamente, nem tudo são vantagens para um empreendedor maduro. Além das condições de saúde geralmente bem mais desfavoráveis que pessoas mais jovens, existem outras dificuldades para esse público. Uma desvantagem dos empreendedores maduros seria a forma cristalizada com veem os negócios e o mundo. Muitas vezes eles buscam dados que confirmem suas ideias (os economistas chamam isso de "viés de confirmação") o que pode ser negativo em um mundo em constante mudança. Esse viés está muito ligado à experiência profissional em um setor trazida por um empreendedor maduro. Nesse sentido, Storey (1994) argumenta que experiência anterior apresenta um comportamento dual: por um lado, essa experiência é útil na identificação de gaps na oferta de produtos em um setor. Por outro lado, esse conhecimento pode ocultar do empreendedor outras novas oportunidades e perspectivas de negócios.

Outra desvantagem óbvia de empreendedor maduro seria a dificuldade de uma pessoa que nunca empreendeu na vida, decidir-se pelo empreendedorismo. Ao contrário de um sistema em que os pagamentos mensais traziam previsibilidade financeira, não existe em um novo negócio qualquer garantia de entradas financeiras. Considerando-se que no Brasil temos condições bastante desfavoráveis para abrir um negócio, esse público fica extremamente relutante em empreender.

Para mitigar desvantagens do empreendedor maduro, conjuntamente com a metodologia effectuation, pode-se utilizar ferramentas como a Mentoria e o Design Thinkingvisando o desenvolvimento de soluções que efetivamente tenham maior probabilidade de sucesso.Apesar de ser potencialmente útil para empreendedores de qualquer idade, a efetividade da mentoria para apoio ao empreendimento de pessoas maduras foi verificada em vários países. O Manual de Boas Práticas para o Empreendedorismo Sênior (EuropeanComission, 2016) enfatiza o valor da mentoria no apoio a projetos empreendedores de seniores. O manual conclui que empreendedores seniores se beneficiariam de programas de mentoria, mas essa técnica isoladamente não geraria mais empreendedores. Logan (2014) concluiu que mentores bem treinados poderiam fazer uma diferença no grupo das mulheres empreendedoras mais velhas pesquisadas no seu estudo, particularmente no sentido de ajudalas a desenvolverem seus negócios. Estudos promissores no uso de jovens empreendedores na mentoria de empreendedores mais velhos têm sido realizados nos Estados Unidos (Kaufmann Foundation 2014). Esses estudos sugerem ganhos dessa mescla de gerações, a qual tem sido caracterizada como ExperiencedEconomy.

Finalmente, o Design Thinking seria outra ferramenta útil para todo o empreendedor (Pinheiro, 2015), principalmente para minimizar o viés de confirmação de pessoas maduras. Através dessa ferramenta, procura-se compreender as necessidades dos usuários e conhecer diversas situações do contexto em que eles estejam envolvidos. Dessa forma, evita-se o

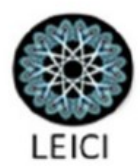


desenvolvimento de produtos de dentro (empreendedor) para fora (usuário), que é a maneira tradicional de solução de problemas em organizações tradicionais que foram escolas profissionais para as pessoas maduras. O Design Thinking "força" a característica empatia no empreendedor, tendo em vista a busca de se colocar no lugar do cliente e entender as suas dores com problemas atuais e necessidade de solucioná-los.

\section{Conclusões}

Pessoas maduras representam um contingente que cresce cada vez mais no Brasil e no mundo. Apesar do rico capital acumulado, os percentuais dessas pessoas que empreendem pela primeira vez ainda são baixos. Dessa forma vemos a questão do empreendedorismo de pessoas maduras como uma questão de inclusão das mesmas no desenvolvimento econômico do país. Entendemos que essa inclusão seria facilitada por mudanças na educação empreendedora, a qual tradicionalmente é voltada para pessoas jovens. Propomos neste trabalho a adoção da metodologia Effectuation, que se mostra promissora na formação de empreendedores seniores. Tendo em vista que o Brasil possui um alto grau de incerteza (econômica, política, social) em relação ao futuro, uma metodologia que se concentre em criar diversas possibilidades futuras, em vez de prevê-las seria muito bem-vinda.

A utilização da Mentoria ajudaria no desenvolvimento de projetos empreendedores seniores, até mesmo quando jovens empreendedores bem-sucedidos viessem a atuar como mentores desse grupo (a chamada mentoria reversa). Isso ajudaria não apenas na inclusão de pessoas maduras nas estatísticas de novos empreendedores, assim como ajudaria a encurtar o gap de relacionamento entre pessoas dessas gerações.

Muito embora a nossa discussão neste artigo esteja centrada em uma metodologia mais adequada para o empreendedorismo maduro, não podemos esquecer as condições sociais dificultando esse tipo de empreendedorismo. Primeiro, o apoio familiar é crucial para esses empreendedores. Logan (2014) encontrou que o apoio familiar crítico para o sucesso do negócio de mulheres maduras. $\mathrm{O}$ apoio da sociedade é uma condição levantada em vários países visando remover o sentimento de desconfiança relativo ao empreendimento maduro (EuropeanComission, 2016). Finalmente, governos devem focar atenção no desenvolvimento de políticas públicas para esse tipo de envelhecimento. Ter uma massa crescente de pessoas que venham a empreender gerando multiplicadores econômicos (e aumentando arrecadação de impostos) em vez de passivamente viverem dos proventos da aposentadoria seria um grande ganho para o sistema econômico-social. E proporcionaria condições de vida mais plena para um segmento que já representa uma maioria em alguns países desenvolvidos e em breve será maioria também no Brasil. 


\section{Referências}

CMI, UK "Boomerpreneurs" to Hit Two Million by 2020, Chartered Management Institute, 2014. Acessado em: http://www.managers.org.uk/insights/news/2014/august/ukboomerpreneurs-to-hit-two-million-by-2020 em fevereiro 2018.

Sized

Cressy, R \&Storey, D., New Firms and their Banks, Centre of Small and Medium

Enterprise, Warwick University Business School and NatWest Bank,Warwick and London,December, 1995.

Curran, J. Blackburn, A., Older People and the Enterprise Society: Age and SelfEmployment Propensities. Work, Employment \& Society / Volume 15 / Issue 04 /pp 889 902, 2002.

European Comission,Senior Entrepreneurship Good Practices Manual, DOI 10.2826/014341, 2016.

GEM Empreendedorismo no Brasil, Relatório Executivo Global Entrepreneurship Monitor, 2015.

Harms, R., Luck, F., Kraus, S., Walsh, S., On the motivational drivers of gray entrepreneurship: An exploratory study. TechnologicalForecasting\& Social Change, 89, 358$365,2014$. 2017.

IBGE Relatório Executivo acessado em https://jornalggn.com.br/noticia, novembro

IBGEBrasil vai se tornar um país de idosos já em 2030, Relatório executivo acessado em https://www.terra.com.br/noticias/brasil/brasil-vai-se-tornar-um-paisde-idosos-ja-em-2030-diz-ibge,91eb879aef2a2410VgnVCM10000098cceb0aRCRD.html, 2013

KAUFMANN FOUNDATION RelatórioExecutivoThe challenges and advantages of senior entrepreneurship 2014, acessadoemhttp://www.kauffman.org, novembro 2017.

Kautonen, T., Tornikoski, E. T., Kibler, K. Entrepreneurial intentions in the third age: the impact of perceived age norms", Small Business Economy, 37:219-234, 2011.

Lèvesque, M., Minniti, M., The effect of aging on entrepreneurial behavior. Journal of Business Venturing 21, 177-194, 2006.

Logan, J., "An exploration of the challenges facing women starting business at fifty", International Journal of Gender and Entrepreneurship Vol. 6 No. 1, pp. 83-96, 2014. 
Pinheiro, T. "The Service Startup - Inovação e Empreendedorismo através do Design Thinking, ALTA BOOKS Editora, Rio de Janeiro, 2015.

Primo, M. A. M., Empreendedorismo como Opção de Inclusão das Pessoas Maduras no Desenvolvimento Econômico e Social, II Simpósio Internacional de Geografia do Conhecimento e Inovação - II SIGCI, Recife, 2017.

Read, S.,Sarasvathy, S. D., Knowing what to do and doing what you know: Effectuation as a form of entrepreneurial expertise.The Journalof Private Equity, Vol. 9, No. 1, pp. 45-62, Winter 2005.

Salusse, M. A. Y., Andreassi, T., O Ensino de Empreendedorismo com Fundamento na Teoria Effectuation, RAC, Rio de Janeiro, v. 20, n. 3, art. 3, pp. 305-327, Maio/Jun. 2016

Sarasvathy, S. D. Causation and effectuation: toward a theorial shift from economic inevitability to entrepreneurial contigency. Academy of Management Review, 26(2), 243-263, 2001.

Singh, G., DeNoble, A., Early Retirees As the Next Generation of Entrepreneurs, Entrepreneurship Theory and Practice, DOI 1042-2587-01, 207-226, Spring 2003.

Zissimopoulos, J.M., Karoly, L.A., Transitions to self-employment at older ages: The role of wealth, health, health insurance and other factors Labour Economics 14, 269-295, 2007. 